\title{
(2) OPEN ACCESS \\ Learning from successes: designing medication adherence intervention research so that we can learn what works and why
}

\author{
Sara Garfield (1) , ${ }^{1,2,3}$ Gaby Judah ${ }^{4}$
}

\begin{abstract}
${ }^{1}$ Centre for Medication Safety and Service Quality, Imperial College Healthcare NHS Trust, London, UK

${ }^{2}$ UCL School of Pharmacy, London, UK

${ }^{3}$ Patient Safety Translational Research Centre, Imperial College London, London, UK ${ }^{4}$ Department of Surgery and Cancer, Imperial College London, London, UK
\end{abstract}

\section{Correspondence to}

Dr Sara Garfield, Imperial College Healthcare NHS Trust, London W2 1NY, UK; sara.garfield@nhs.net

Accepted 1 July 2021

\section{Sinked}

- http://dx.doi.org/10.1136/ bmjqs-2020-011671

\section{Check for updates}

(c) Author(s) (or their employer(s)) 2021. Re-use permitted under CC BY-NC. No commercial re-use. See rights and permissions. Published by BMJ.

To cite: Garfield S, Judah G. BMJ Qual Saf Epub ahead of print: [please include Day

Month Year]. doi:10.1136/

bmjqs-2021-013381
"Drugs don't work in patients who don't take them"-C.E. Koop, US Surgeon General $^{1}$

Even if clinicians prescribe the most appropriate medications for their patients, the effectiveness of these depends on how patients take them. ${ }^{1}$ Adherence presumes an agreement between prescriber and patient about the prescriber's recommendations ${ }^{2}$ and is defined as the extent to which the patient's action matches the agreed recommendations. ${ }^{2}$ Low adherence is associated with adverse outcomes, hospitalisation and increased mortality. ${ }^{3}$ It is therefore a source of avoidable patient harm, as well as increased healthcare costs and reduced cost-effectiveness of medicines. ${ }^{4-7}$ However, approximately 30\%-50\% of patients with long-term conditions are estimated to be non-adherent to their medication. ${ }^{4} \mathrm{~A}$ systematic review has found that while many studies have evaluated the effects of interventions to increase adherence, most appear to have limited effects. ${ }^{8}$ Of 182 randomised controlled studies, only 17 had a low risk of bias, and only 5 of these demonstrated an increase in both adherence and clinical outcomes. ${ }^{8}$ In addition, these effects were generally small, and interventions were complex and not necessarily scalable to routine clinical practice. The authors of the review concluded that it was not possible to make generalisations about what types of interventions work and which do not. This lack of clear recommendations for intervention design is a challenge to researchers as well as to clinicians trying to improve medication adherence.

The publication in this issue ${ }^{9}$ of the evaluation of an adherence intervention with a large sample size, that both increased adherence and improved clinical outcomes, is therefore a helpful addition to the literature. In this study, Torres-Robles and colleagues report a cluster randomised controlled trial of an individually tailored intervention to increase medication adherence in patients with hypertension, asthma or chronic obstructive pulmonary disease. The intervention was delivered by community pharmacists in Spain, over face-to-face visits held once a month for 6 months. Ninety-eight pharmacies were included and randomised to intervention or control groups, and 1038 patients completed the trial. The protocolised intervention included an initial interview to assess adherence and classify reasons for nonadherence as intentional (eg, perceptual barriers such as concerns about side effects), unintentional (eg, practical barriers such as forgetting) or both. The pharmacist then used tailored strategies based on the type of non-adherence and the barriers identified, including motivational interviewing principles. Patient progress was reviewed in the follow-up visits, with feedback, or new strategies provided to improve or maintain adherence. The control group received usual care. After 6 months, more participants in the intervention group were found to be adherent, using a validated self-report adherence scale commonly used in adherence research, ${ }^{10}$ with an absolute increase in the percentage of adherent patients of $51.8 \%$ in the intervention group, and $22.2 \%$ in the control group, from baseline rates of $39.1 \%$ and $44.3 \%$, respectively (OR of 5.12 for being adherent, $\mathrm{p}<0.05$ ). Importantly, the intervention group had better scores in disease-specific outcomes for all conditions compared with control participants. 
The study has some important limitations, including the use of self-report rather than objective adherence measures. However, there is no gold standard for the measurement of medication adherence, and self-report measures correlate well with electronic monitoring devices. ${ }^{11} \mathrm{~A}$ further important limitation is that measurement of outcomes did not continue past the end of the intervention-it is therefore not known whether the improved adherence can be expected to be sustained after the intervention has finished. Previous research has suggested that adherence interventions may need to be continued long term for some patients to achieve sustained effects on adherence. ${ }^{12}$ Notwithstanding these limitations, the demonstration of a positive intervention effect over the relatively long term, and in disease outcomes in addition to adherence, is highly promising. The key questions are: what can we learn from this study and other adherence interventions in terms of how to effectively increase medication adherence in a scalable and sustainable way? And what makes such interventions successful, and how can they be applied to other populations and conditions to improve health outcomes and reduce healthcare costs associated with poor adherence?

In order to answer these important questions, it is crucial to be able to identify which specific aspects of effective interventions lead to their success. For example, in Torres-Robles and colleagues' study ${ }^{9}$ was it the tailored and protocoled intervention process supporting participants with appropriate behavioural techniques needed for change in behaviour, the application of theory through the Transtheoretical Model of behaviour change, ${ }^{13}$ participants having attention from multiple individual face-to-face sessions, or expert intervention delivery specifically by community pharmacists? Alternatively, is the whole intervention required to be carried out, as in the trial, to achieve these results? When reporting trial findings, inclusion of some process evaluation approaches may shed light on which aspects contribute most to the improvements seen. Key factors to consider when doing a process evaluation of a medication adherence intervention include tailorability, acceptability, scalability and sustainability.

Previous research has shown that individually tailored interventions are likely to be effective at changing behaviour, ${ }^{14}$ through recognising and addressing the varying barriers people face to medication adherence, instead of a one-size-fits-all approach. Tailoring has not always been included in previous pharmacy-based medication adherence interventions. ${ }^{15}$ To enable others to learn from effective tailored interventions, studies must include details of the steps and methods used to tailor the intervention, for example, exactly how barriers were identified, and how the selected techniques were implemented. As with any behavioural intervention, it is essential to clearly specify the active ingredients of the behavioural intervention-the behavioural techniques prompting changes in behaviour. A practical and evidencebased way of doing this is with the Behaviour Change
Techniques taxonomy, ${ }^{16}$ which provides recognised and consistent terminology to describe the behavioural components of an intervention. When reporting tailored interventions, data on the frequency of use of each of the listed intervention options may also inform researchers and practitioners as to the more common barriers in the population. For example, for the Torres-Robles study, it would have been beneficial to know the proportion of participants from each medical condition reporting intentional or non-intentional barriers to adherence, or a combination. Understanding this profile, and how this may change according to condition, age or other demographics, would be valuable to those designing interventions to promote adherence, and assist in suggesting the types of intervention components which may be effective in other populations and settings. Related to this, some aspects of the reported intervention addressed barriers linked to specific conditions (eg, medication techniques, or beliefs about a particular condition), whereas others were related to adherence more generally (eg, forgetfulness). Given the prevalence of multi-morbidity, knowing whether there is an optimum balance between assessing and addressing the general or specific medication barriers would be helpful knowledge. We can only establish this if details, such as the amount each technique was used, are measured and reported.

In addition to learning which aspects of the intervention itself led to the success, it would be helpful to understand more about what motivated healthcare professionals and patients to take part, particularly as no incentives were offered to pharmacists to provide the service. Torres-Robles and colleagues recruited a large number of pharmacies into their study, although the number of pharmacies originally approached is not given. The dropout rate for both pharmacies and pharmacists after recruitment was relatively low, suggesting that the intervention was reasonably acceptable. Future work could include interviewing the pharmacists to explore the factors supporting this high retention, so that this could be replicated in future work. Pharmacists' views on the intervention, the reasons for its success, what worked well and what could be improved further, would help inform future studies. It would be interesting to know how provision of the intervention fitted within the current remuneration structure for pharmacists in Spain, to support incorporation of the intervention into healthcare systems in other countries. Likewise, it would be beneficial to evaluate the response rate from patients, any differences between responders and nonresponders, and what motivated patients to take part. It would also be helpful to know patients' perspectives on the time commitment, what worked well and what could make the intervention even more effective.

It is also important to consider whether the intervention can feasibly be scaled up within routine clinical practice and can be sustained beyond six sessions if needed. Multiple face-to-face visits with a community pharmacist may not always be feasible. Further research 
could potentially establish whether or not the intervention content in Torres and colleagues' paper could be effectively delivered in a different format (eg, via text messages, an app or paper-based tool) and/or by different staff. Systematic reviews have found tailored digital health interventions to be effective in changing a variety of health behaviours and outcomes; however, the observed effect sizes have been variable. ${ }^{17-19}$ A hybrid model combining a smaller number of face-to-face sessions with community pharmacists, with a digital or paper tool, may be a promising option for implementing the same behavioural tools and intervention tailoring, by staff with the same high level of expertise and authority, but in a way that is more scalable, practical and costeffective within clinical practice.

To conclude, testing the effects of adherence interventions on health outcomes is a crucial part of their evaluation. However, conducting in-depth process evaluations are also important if we are to capitalise on the success of effective interventions. This approach may help in identifying which aspects of interventions were critical to their success, and establishing how these can be replicated and scaled up as cost-effectively as possible. In addition, measuring and reporting the views of patients, family carers and healthcare professionals on the tailorability acceptability, accessibility and sustainability of such interventions may inform development of future interventions that are both high impact and scalable, and therefore help address this so far elusive challenge.

\section{Contributors SG and GJ wrote the editorial.}

Funding The authors are supported by the National Institute for Health Research (NIHR) Imperial Patient Safety Translational Research Centre (grant refererence PSTRC-2016-004).

Disclaimer The views expressed in this publication are those of the authors, not necessarily those of the NHS, the NIHR or the Department of Health and Social Care.

Competing interests None declared.

Patient consent for publication Not required.

Provenance and peer review Commissioned; internally peer reviewed.

Open access This is an open access article distributed in accordance with the Creative Commons Attribution Non Commercial (CC BY-NC 4.0) license, which permits others to distribute, remix, adapt, build upon this work noncommercially, and license their derivative works on different terms, provided the original work is properly cited, appropriate credit is given, any changes made indicated, and the use is noncommercial. See: http://creativecommons.org/licenses/by-nc/4. $0 /$.

\section{ORCID iD}

Sara Garfield http://orcid.org/0000-0002-9980-0520

\section{REFERENCES}

1 Koop C. Keynote Address. In: Improving medication compliance: proceedings of a symposium. Reston, Virginia: National Pharmaceutical Council, 1985: 1-4.

2 National Institute of Clinical Excellence. Medicines adherence: involving patients in decisions about prescribed medicines and supporting adherence. London, 2009.
3 Mongkhon P, Ashcroft DM, Scholfield CN, et al. Hospital admissions associated with medication non-adherence: a systematic review of prospective observational studies. BMJ Qual Saf 2018;27:902-14.

4 Elliott R. Non-adherence to medicines: not solved but solvable. J Health Serv Res Policy 2009;14:58-61.

5 Martin-Ruiz E, Olry-de-Labry-Lima A, Ocaña-Riola R, et al. Systematic review of the effect of adherence to statin treatment on critical cardiovascular events and mortality in primary prevention. J Cardiovasc Pharmacol Ther 2018;23:200-15.

6 Taylor F, Huffman MD, Macedo AF, et al. Statins for the primary prevention of cardiovascular disease. Cochrane Database Syst Rev 2013:CD004816.

7 Vrecer M, Turk S, Drinovec J. Use of statins in primary and secondary prevention of coronary heart disease and ischemic stroke. meta-analysis of randomized trials. Int J Clin Pharmacol Ther 2013;14:567-77.

8 Nieuwlaat R, Wilczynski N, Navarro T, et al. Interventions for enhancing medication adherence. Cochrane Database Syst Rev 2014:CD000011.

9 Torres-Robles A, Benrimoj SI, Gastelurrutia MA, et al. Effectiveness of a medication adherence management intervention in a community pharmacy setting: a cluster randomised controlled trial. BMJ Qual Saf 2021. doi:10.1136/bmjqs-2020-011671. [Epub ahead of print: 29 Mar 2021].

10 Morisky DE, Green LW, Levine DM. Concurrent and predictive validity of a self-reported measure of medication adherence. Med Care 1986;24:67-74.

11 Shi L, Liu J, Koleva Y, et al. Concordance of adherence measurement using self-reported adherence questionnaires and medication monitoring devices. Pharmacoeconomics 2010;28:1097-107.

12 Musiimenta A, Atukunda EC, Tumuhimbise W, et al. Resilience after withdrawing a technology-based medication adherence support intervention from people living with HIV in rural Uganda. AIDS Care 2018;30:S89-96.

13 DiClemente CC, Prochaska JO, Fairhurst SK, et al. The process of smoking cessation: an analysis of precontemplation, contemplation, and preparation stages of change. J Consult Clin Psychol 1991;59:295-304.

14 Clifford S, Garfield S, Eliasson L, et al. Medication adherence and community pharmacy: a review of education, policy and research in England. Pharm Pract 2010;8:77-88.

15 Anderson M, Garfield S, Eliasson L. Delivery of patient adherence support: a systematic review of the role of pharmacists and doctors. Patient Intell 2014;6:31-42.

16 Michie S, Richardson M, Johnston M, et al. The behavior change technique taxonomy (V1) of 93 hierarchically clustered techniques: building an international consensus for the reporting of behavior change interventions. Ann Behav Med 2013;46:81-95.

17 Lustria MLA, Noar SM, Cortese J, et al. A meta-analysis of web-delivered tailored health behavior change interventions. $J$ Health Commun 2013;18:1039-69.

18 Ryan K, Dockray S, Linehan C. A systematic review of tailored eHealth interventions for weight loss. Digit Health 2019;5:205520761982668.

19 Sahin C, Courtney KL, Naylor PJ, et al. Tailored mobile text messaging interventions targeting type 2 diabetes selfmanagement: a systematic review and a meta-analysis. Digit Health 2019;5:205520761984527. 